\section{耍 Heighten Science \\ P U B L I C I T I O N S Corporation ISSN 2575-0186}

\title{
The Effect of Cement and wrapping on the Decomposition rate of the Rabbit Carcasses
}

\author{
Lai Poh Soon ${ }^{1 *}$, Khoo Lay See ${ }^{1}$, Nazni Wasi Ahmad ${ }^{2}$, Azlina \\ Zulkapli ${ }^{3}$, Nurul Kharmila Abdullah', Mohd Shah Mahmood ${ }^{5}$ \\ and Ahmad Hafizam Hasmi ${ }^{5}$ \\ 'Forensic Scientific Officer of Institute of Forensic Medicine Malaysia, Kuala Lumpur Hospital, \\ Malaysia \\ ${ }^{2}$ Forensic Entomologist, Unit of Entomology, Institute of Medical Research, Malaysia \\ ${ }^{3}$ Veterinary Officer, Unit of Animal Care, Institute of Medical Research, Malaysia \\ ${ }^{4}$ Senior Lecturer and Forensic Pathologist, University of Science Islamic Malaysia, Kuala \\ Lumpur Hospital, Malaysia \\ ${ }^{5}$ Forensic Pathologist, Institute of Forensic Medicine Malaysia, Kuala Lumpur Hospital, \\ Malaysia
}

*Address for Correspondence: Dr. Lai Poh Soon, Forensic Scientific Officer of Institute of Forensic Medicine Malaysia, Kuala Lumpur Hospital, Malaysia; Tel: +603 2690 6694, Fax: +603 2694 1422; Email: roysonn1@hotmail.com

Submitted: 08 August 2017

Approved: 15 August 2017

Published: 16 August 2017

Copyright: @ 2017 Soon LP, et al. This is an open access article distributed under the Creative Commons Attribution License, which permits unrestricted use, distribution, and reproduction in any medium, provided the original work is properly cited.

Keywords: Taphonomic study; Rabbit; Wrapping; Cement; Decomposition rate

\section{ABSTRACT}

Taphonomic study was first time conducted in Kuala Lumpur, capital city of Malaysia. In this research model, male Oryctolagus cunicullus weighed $1.8-2.6 \mathrm{~kg}$ each were killed by Dolethal intravenously at the ear region. In Phase 1 study, eight subjects were wrapped in a sack and cemented within a container to be compared with the other four controls at each location labelled A (ground) and B (manmade freshwater pond). Phase 2 involved duplicating set of 15 cemented samples comparable to 1 control made up to total of 32 subjects which were all put into a compact polytank containing freshwater to simulate a case study. Taphonomic changes were observed and scored using TBS system incorporating of fresh stage, early decomposition stage, advanced decomposition stage and skeletonisation stage. The ambient temperature of surroundings with $28.81 \mathrm{C} \pm 4.21^{\circ} \mathrm{C}$ and $29.21^{\circ} \mathrm{C} \pm 4.57^{\circ} \mathrm{C}$ (mean \pm S.D.) while relative humidity of air with $74.49 \% \pm 14.61 \%$ and $79.15 \% \pm 16.32 \%$ (mean \pm S.D.) were recorded for Phase 1 and Phase 2 study respectively. Time taken for ground control exposed and wrapped carcasses to reach first sign of skeletonised stage were four days and five days respectively. Whilst freshwater controls reached initial skeletonised stage within one week for exposed carcass and two weeks for wrapped carcass. Within the control and cemented sample carcasses, TBS scores increased from initial stages of decomposition and become plateau after advanced decomposition. The cementing factor have superseded the wrapping factor due to its stronger physical barrier effect to slow down the decomposition more than half compared to controls based on Multiple way ANOVA test. Phase 2 study has demonstrated more accurately on the decomposition rate of the cemented samples. It showed that wrapping and cementing factors have delayed the decomposition process of the rabbit carcasses about 4 times to reach the initial stage of skeletonisation compared to the control carcasses. There was absence of insect activity within the cemented samples, hence the microorganism activity would be the only contributor to the decaying process within the cemented samples at slower rate comparing to the exposed or wrapped controls.

\section{INTRODUCTION}

Taphonomic study is a research which includes various discipline such as decomposition process, preservation, dispersion, buried and exposition of dead body [1]. Forensic taphonomy is an international endeavour which includes collecting the evidence in crime scene and interpretation of dead cases [2]. Forensic taphonomy is often linked with ecological aspect because carcass is considered as newly emerging microenvironment [3]. Taphonomic study is also an actualistic research which shares common fundamental between traditional, paleontological taphonomy and forensic taphonomy [4]. Taphonomic study usually on adult Sus scrofa domestica is a study to 
mimic the real human body decomposition [5]. Murder case is quite common and the body is usually dumped in the rural area or open field in jungle. Hence, the important thing is that we would like to find out the decomposition rate and taphonomic changes in order to deduce the post-mortem interval as well as estimation of time of death.

Apart from that, cadaver is the food source that will initiate the complex cycle of tropic phase like decomposition process, assimilation, and dispersion [5]. Cadaver also caused the chemical, temperature and soil composition changes of the environment $[6,7]$. Thus, taphonomic research is very dependent on the environmental factor and local condition such as atmosphere, lithosphere, biosphere, decomposition process, preservation technique and condition of buried [8]. During the decomposition process, cadaver is broken down into smaller material and will be absorbed into the soil, washed away by rain, eaten up by insects or evaporated into the air [2]. Taphonomic data is useful as forensic evidence to determine original death place, ways of transportation body, criminal activities, and post-mortem interval determination [8].

Forensic pathologists are often faced with the task of establishing an accurate estimation of the time of death or post-mortem interval (PMI). The estimation of PMI is crucial for ongoing criminal investigations in order to identify or eliminate suspects, to reconstruct events and circumstances surrounding death. An estimation of PMI may also be required for judiciary implications in questions of the manner of death whether homicide, natural, accidental or suicide consistent with the alibi and witness statements [9]. PMI estimation is crucial in forensic sciences for both positive identification and reconstruction of perimortem events. In order to solve a problem of misidentification in year 2006, South Branch of Portuguese National Institute of Legal Medicine carried out the exhumation of 25 identified individuals buried for 5 years in the same cemetery plot. Even though all individuals shared similar PMI, they presented different stages of decomposition due to micro taphonomic environments and individual endogenous factors [10].

There are various methods available to forensic anthropologists for providing an accurate PMI. A pathologist performs the PMI assessments based on the post-mortem changes in soft tissues such as stiffness (rigor mortis), settling of blood (livor mortis), body cooling (algor mortis), and other stages of decomposition subject to considerable variation and diverse environments. The previous research studies help explore various factors related to the condition of the body, health of the individual, or the surrounding environment and climate that may affect and alter the rate of decomposition and insect activity. In addition to observational techniques, there are mathematical models or statistical tools that include all of the variables listed above for PMI estimations. Other authors claim using the temperature method or the chemistry of body fluid alone can produce maximum precision within a statistical confidence interval of $95 \%$ depending on the PMI, availability of equipment, circumstances of the death, and environment [10].

In Malaysia, there were several researches conducted to evaluate the insect succession pattern as well as decomposition process of pigs in palm oil plantation $[11,12]$. Malaysia is located in Equator. Equatorial climate in Malaysia contribute to high and stable temperature throughout the year with annual mean temperature of $27.3^{\circ} \mathrm{C}$. The current taphonomic study was conducted in Hospital Kuala Lumpur. In this research model, male Oryctolagus cunicullus weighed 1.8-2.6 kg each were selected. Oryctolagus cunicullus as a human analogue was an acceptable manner for scientific research. Apart from that, the decomposition process for Oryctolagus cunicullus was almost same with the human cadaver under the same environment condition. The goal of this research was to estimate the rate of decomposition on a rarely occurring circumstance whereby human cadaver was wrapped and cemented found in a forensic context. Authors attempted, by using rabbit carcasses, to determine decomposition rate affected by the wrapping and cemented conditions within manmade freshwater 
pond environments. Decomposition rate were compared amongst the controls and subjects. This research, hence, will assist in simulating the actual homicidal cases involving victim's body that was found with wrapping and cemented and left in a drain area [9].

\section{LITERATURE REVIEW}

Taphonomic studies regularly employ animal analogues for human decomposition due to ethical restrictions relating to the use of human tissue. A study was conducted to compare the decomposition of skeletal muscle tissues from human (Homo sapiens), pork (Sus scrofa), rabbit (Oryctolagus cunicullus), lamb (Ovis aries), and beef (Bos taurus) interred in soil microcosms. The overall patterns of nutrient fluxes and chemical changes in non-human tissues and the underlying soil followed that of human tissues. Though no single analogue was a precise predictor of human decomposition in soil, all models offered close approximations in decomposition dynamics [13].

Exogenous factors may affect decomposition changes included exposure to elevated environmental temperatures, both outdoors and indoors, exacerbated by increased humidity or fires. Deaths within motor vehicles were also characterized by enhanced decomposition. Failure to quickly or adequately refrigerate bodies may also lead to early decomposition. Artefactual-enhanced putrefactive and autolytic changes may be misinterpreted as indicating a prolonged post-mortem interval and induce doubt on the reliability of witness statements. In addition, endogenous factors may also affect decomposition changes included fever, infections, illicit and prescription drugs, obesity and insulindependent diabetes mellitus. When these factors are identified at autopsy, it should be correlated to changes of decomposition as markers of time since death [14].

Nevertheless, the data comparison from many environments and temperatures shows no difference in decomposition progression when measured using accumulated degree days (ADDs). The major effector of change in rate was insect presence, regardless of species, depositional environment, or season [5]. In different seasons and forests, pattern of decomposition was the same in almost all cases with putrefaction, active and advanced decay. Season significantly affected rate of active decay due to a much higher rate in summer [15]. Body size is significant when carcasses are accessed by insects; when insects are excluded, while bodies are indoors, submerged, or buried, then decomposition progresses at the same rate regardless of body size [16]. However, another project was aimed to compare decomposition rates of large pigs $(60-90 \mathrm{~kg})$ with that of small pigs $(<35 \mathrm{~kg})$ in order to assess the influence of body size on decomposition rates. Stages of decomposition were scored according to separate categories for each anatomical region, and the point values for each region were added to determine the total body score (TBS), which represents the overall stage of decomposition for each pig. Results indicated that rapid decomposition occurs during the early stages of decomposition for both samples. Large pigs showed a plateau phase in the course of advanced stages of decomposition, during which decomposition was minimal. A similar but much shorter plateau was reached by small pigs of $>20$ $\mathrm{kg}$ at a PMI of 20-25 days and after which decomposition commenced swiftly. This was in contrast to the small pigs of $<20 \mathrm{~kg}$, which showed no plateau phase and their decomposition rates were swift throughout the duration of the study. Overall, small pigs decomposed 2.82 times faster than large pigs, indicating that body size does have an effect on the rate of decomposition [17].

The study of decomposition by using ADDs has also been suggested not only in terrestrial decay but also for water-related deaths. In most of bodies, freshly formed adipocere was able to delay the appearance of later decompositional stages explaining why most of the bodies were in relatively good condition. The accuracy of the decompositional scoring system (DSS) can be affected by adipocere and animal activity. DSS model gives a false perception of accuracy due to the complexity of 
integrating all changing factors affecting human decay in environments such as animal activity, temperatures, and depth of submersion/burial [19]. Protocols for determining post-mortem submersion interval (PMSI) have long been problematic for forensic investigators due to the wide variety of factors affecting the rate of decomposition of submerged carrion. The human analogue should be examined at depth using the total aquatic decomposition (TAD) scoring system to calculate an approximate PMSI [20].

On the other hand, the influence of clothing and wrapping on carcass decomposition and arthropod succession was investigated to provide data to enable estimated PMI in homicide investigations. Six pig carcasses were divided into three sample groups, each with a clothed carcass wrapped and a carcass wrapped with no clothes. The results showed that clothed or wrapped carcasses had larger visible maggot masses, which moved more freely and these carcasses took longer to dry out [18]. The effect of clothing on carcass decomposition and patterns of insect succession onto remains were also investigated during autumn in Western Australia. The progression of decomposition differed between clothed and unclothed carcasses in both years of the study. The presence of clothing markedly prolonged the wet decay stage in both years with larval feeding occurring across the moist skin surface underneath clothing, as well as within and under the carcasses. Ambient temperatures were higher in the second year of the study and corresponded to marginally faster rates of decay throughout decomposition. Within years, insect arrival and oviposition were largely consistent between clothed and unclothed carcasses with a few notable exceptions. Dipteran larval masses were more widely distributed across the carcass surface and were present for a longer period of time on clothed carcasses than on unclothed carcasses in both years [21].

Of the many factors that affect buried remains, one that is particularly pertinent to forensic studies is the inclusion of lime in a burial. It would seem that assailants believe that lime accelerates the decomposition of soft tissues in buried remains. However, observations by forensic investigators suggest that lime actually tends to slow the decomposition of buried remains. A study was conducted on a farm in northwestern Indiana between 1995 and 1998 and examined three variables influential to decomposition: duration of burial, depth of remains below the surface, and the presence or absence of lime. Pits 1 and 2 were deep burials interred for thirty months. Pits 3 and 4 were shallow burials interred for six months. Pits 5 and 6 were deep burials interred for six months. Upon excavation, each pig was given a numeric score based on the degree of decomposition it exhibited. The results show that lime does not significantly slow the rate of decomposition of buried remains. The greatest difference in preservation between the limed and non-limed (control) burials occurred in shallow, six-month pits (Pits 3 and 4). It appears that the preserving qualities of lime decrease over time and are not as influential at greater depths [23]. Recent casework in Belgium involving the search for human remains buried with lime, demonstrated the need for more detailed understanding of the effect of different types of lime on cadaver decomposition and its micro-environment. Lime is a generic term used to cover quicklime ( $\mathrm{CaO})$, hydrated lime $\left(\mathrm{Ca}(\mathrm{OH})_{2}\right)$ and non-pure derivatives such as hydraulic lime. Six pigs (Sus scrofa) were used as body analogues in field experiments. They were buried without lime, with hydrated lime $\left(\mathrm{Ca}(\mathrm{OH})_{2}\right)$ and with quicklime $(\mathrm{CaO})$ in shallow graves in sandy loam soil in Belgium and recovered after 6 months of burial. Observations from these field recoveries informed additional laboratory experiments that were undertaken at the University of Bradford, UK. The combined results of these studies demonstrate that despite conflicting evidence in the literature, hydrated lime and quicklime both delay the decay of the carcass during the first 6 months [24].

Cement is made from limestone $\left(\mathrm{CaCO}_{3}\right)$ that is crushed, finely ground, mixed with clays, and heated to nearly 3,000 degrees in large rotary kilns that are typically fired with oil, gas, or coal dust. The heat-treated material, called "clinker" is ground to powder and mixed with a small amount of gypsum. Cement is often sold to "ready-mix" operators who custom-mix and deliver batches of liquid concrete to construction sites, 
but some cement manufacturers make their own ready-mix concrete [25]. Concrete is made by mixing cement with sand and rock (called "aggregate") and water. The proportions of these ingredients, and the types of aggregate, determine the concrete's physical characteristics. Concrete begins to set within a few hours after being mixed, although total curing takes many days [26]. Cement combination that contains CEM I, fly ash, silica fume and metakaolin for durability design against carbonationinduced corrosion in concrete. Loss of passivation and corrosion of reinforcement in the presence of moisture and oxygen would occur when carbonation reduces the $\mathrm{pH}$ of pore water from about 12.6-13.5 to about 8.3-9.0 [27]. For instance, there was a research conducted on cemented pig carcasses. It showed areas of mummification at the abdomen within a general context of initial putrefaction at the third-month time interval whilst showed a wide adipocere formation after six- month period of time [28].

\section{OBJECTIVES}

\section{General Objectives}

i. To simulate a case study on the factors affecting the decomposition rate of a cadaver under outdoor environment.

\section{Specific Objectives}

i. To correlate between TBS scores and the decomposition rate

ii. To determine the effect of wrapping and cement on the decomposition process

\section{Null Hypothesis}

i. TBS scores do not correlate with the decomposition rate

ii. Wrapping and cement do not affect the decomposition rate of a cadaver

\section{Hypotheses}

i. TBS scores directly proportionate with the decomposition rate

ii. Wrapping and cement slows down the decomposition process.

\section{METHODOLOGY}

\section{Study Design}

During Phase 1 study, twelve 4-month-old males of Oryctolagus cunicullus weighed 1.8-2.2 kg each were used in this study. All of them were killed by 10.0-15.0 ml Dolethal intravenously near the ear region at Animal Unit of Institute of Medical Research, Kuala Lumpur in the evening whenever blow fly was inactive during nocturnal condition $[29,30]$. After that, all the carcasses were put into the boxes and wrapped with plastic bags while waiting to be transferred to study site at National Institute of Forensic Medicine, Hospital Kuala Lumpur. Later, four controls of New Zealands white rabbits were put separately on top of the ground of grassland and manmade 650-litre freshwater pond (cylindrical shape with $180 \mathrm{~cm}$ in diameter and $30 \mathrm{~cm}$ in height) which were then labelled as Site A and Site B. Both the study sites were 5 meters away from each other. Codon area $(3 \mathrm{~m} \times 3 \mathrm{~m})$ was set up to restrict from entrance to the study site despite the fence was locked from the main entrance as well. These four control rabbits with two at each Site A (GC1 was exposed and GW1 was wrapped in a sack) and Site B (SC1 was exposed and SW1 was wrapped in a sack) were put inside a cage measuring $60 \mathrm{~cm} \mathrm{\times} 40 \mathrm{~cm} \mathrm{X} 50 \mathrm{~cm}$ to prevent the scavenger effect on the carcasses. Another eight sample rabbits were wrapped in a sack separately and cemented (3 gram per $1 \mathrm{ml}$ water) separately inside a biscuit tin measuring $34 \mathrm{~cm}$ x $23 \mathrm{~cm} \mathrm{X} 23 \mathrm{~cm}$. This study was conducted in the late afternoon to avoid attraction of blowflies to the carcasses, which was taken as the Day 0 while waiting for the eight cemented sample rabbits to be dried and subsequently transferred to the Site A (labelled as $\mathrm{GCm}$ ) and Site B (labelled as SCm). 
The Phase 1 of the study was conducted for 40 days based on the control GC1 to become fully skeletonised within 4 days under outdoor normal condition. The hypothesis of ten times delayed was assumed in this study design under wrapping and cemented condition despite there was no existing research had been conducted prior to this. Observations were made on the controls for 40 days with 1 visit per day at 3 p.m. First week observation was conducted at every day basis to evaluate the changes of the carcasses and once in two-day time for the subsequent weeks. Climatological data such as ambient temperature and humidity were recorded for 40 days by using data logger and НОВО recorder software. Adult flies were caught by using sweep net. Some of the fly larvae were collected using forceps and put into ethyl alcohol $70 \%$ for preservation [31]. The specimens were processed for storage and kept as record in the Entomology Unit of Institute of Medical Research (IMR). Post-mortem changes were recorded by Forensic Scientific Officer (FSOs) for all four controls at Site A and Site B from time to time until skeletonisation was onset and both were comparable separately to wrapped and cemented rabbits by breaking open the cements using impact power drill and hammer. The stage of decomposition and the TBS scores were recorded and verified by Forensic Pathologists. The obtained data was analysed to determine the significant differences on the TBS scores in which it may be regarded as inter-rater reliable [32]. Decomposition rate were calculated based on TBS scores over number of days.

The study was continued with Phase 2 study using thirty two 4-month-old male Oryctolagus cunicullus weighed 1.8-2.6 kg each were used in this study. Two of them were act as controls and put into two separate manmade 400-litre freshwater ponds (150 gallon cylindrical compact polytank with $105 \mathrm{~cm}$ in diameter and $98 \mathrm{~cm}$ in height), each labelled as Tank A and Tank B which then allocating for the respective duplicate cemented samples. These two control rabbits were exposed (labelled as CT A and CT B) and put inside a cage measuring $60 \mathrm{~cm} \mathrm{x} 40 \mathrm{~cm} \mathrm{X} 50 \mathrm{~cm}$ to prevent the scavenger effect on the carcasses. The remaining 30 samples $(\mathrm{Cm})$ were wrapped in a sack separately and cemented (3 gram per $1 \mathrm{ml}$ water) separately inside a biscuit tin measuring $34 \mathrm{~cm} \times 23 \mathrm{~cm} \mathrm{X} 23 \mathrm{~cm}$. They were all put into the Tank A and Tank B, each with 15 samples respectively and labelled as $1 \mathrm{~A}-15 \mathrm{~A}$ and 1B-15B. The Phase 2 study was conducted for 60 days based on the results of Phase 1 study that it was almost 10 times slower rate compared to exposed control rabbits in the freshwater pond to start skeletonisation after 6 days. Observations were made for 60 days at four-day interval at $10 \mathrm{a}$.m. including the controls as well as the wrapped and cemented rabbits by breaking open the cements using impact power drill and hammer. The subsequent procedures were almost similar to those mentioned in Phase 1 study.

Decomposition had generally been classified into five observational stages including, fresh (bloated), early decomposition (discoloration), advanced decomposition (first bone exposure), skeletonisation (drying of the bones) and extreme decomposition (dry and weathered). Within each of these stages there are secondary descriptive categories, which do not imply a sequence of events, but describe the overall condition and appearance of the remains [22]. To aid with the problem of establishing an accurate estimation of the rate of decomposition and PMI, it was proposed using observational decomposition stages and assigning each stage multiple categories with a numerical score. Decomposition were divided into four broad stages including, fresh, early decomposition, advanced decomposition and skeletonisation. All four stages of decomposition were assigned to various categories to accurately describe each observational period. A point value system was then assigned to each category shown in (Table 1) and started at one point for the fresh stage and increases by one point for each progressive category. Next, the body was divided into three sections because stages of decomposition did not apply equally to all parts of body. Part one consisted of the head and neck, including the cervical vertebrae. Part two consisted of the trunk, 


\begin{tabular}{|c|c|c|c|c|}
\hline Table 1: Stages of Decomposition (Phase 1). & \multicolumn{3}{|c|}{} \\
\hline Stage & GC1 & SC1 & GW1 & SW1 \\
\hline & Day & Day & Day & Day \\
\hline Fresh & $0-1$ & $0-1$ & $0-2$ & $0-3$ \\
\hline Early Decomposition & $2-3$ & $2-3$ & 3 & 4 \\
\hline Advanced Decomposition & $3-4$ & $4-6$ & 4 & $5-12$ \\
\hline Skeletonisation & $4-8$ & $7-22$ & $5-22$ & $14-40$ \\
\hline
\end{tabular}

including the thorax, pectoral girdle, abdomen, and pelvic girdle. Part three consisted of the upper and lower limbs, including the hands and feet. Then, the score of each of the three anatomical regions were combined to produce a TBS. The lowest score a subject could receive was a 3 , which would appear fresh in all regions, and the highest score was 54 whereby 18 scores for all the three body regions. This would appear completely dry and fully skeletonised [22].

\section{A. Fresh (Cumulative score $=0$ for each parts)}

1. Fresh, no discoloration or insect activity

2. Fresh burned

\section{Early Decomposition (Cumulative score $=2$ for each parts)}

1. Pink-white appearance with skin slippage and some hair loss

2. Gray to green discoloration, some flesh relatively fresh

3. Discoloration to brownish shades particularly at fingers, nose and ears; some flesh still relatively fresh

4. Bloating with green discoloration

5. Post bloating following rupture of the abdominal gases with discoloration going from green to dark

6. Brown to black discoloration of arms and legs, skin having leathery appearance

\section{Advanced Decomposition (Cumulative score $=8$ for each parts)}

1. Decomposition of tissues producing sagging of the flesh, caving in of the abdominal cavity, often accompanied by extensive maggot activity

2. Moist decomposition in which there is bone exposure

3. Some retention of internal structures

4. Outer tissues only with internal organs lost through autolysis or insect activity

5. Bone exposure of less than one half the skeleton

6. Adipocere development

\section{Skeletonisation (Cumulative score $=14$ for each parts)}

1. Bones with greasy substances and decomposed tissue, sometimes with body fluids still present

2. Bones with desiccated tissue or mummified tissue covering less than one half the skeleton

3. Bones largely dry but still retaining some grease

4. Dry bone 


\section{Materials}

1. Canon M16 Digital Camera to take photos and videos

2. Dolethal as Euthanasia

3. Data logger to measure the humidity and temperature

4. Sacks for wrapping

5. Ready-mix concrete to cement the rabbits

6. Impact Power Drill and hammer to break the cement

7. Tins to place the wrapped rabbits and filled with cement

8. Angle Grinder to cut the tin

\section{Ethical Issue}

Animal Ethics approval by Animal Care and Use Committee (ACUC), National Institute of Health, Malaysia was acquired which valid from May 2016 until May 2017.

\section{RESULTS}

During the Phase 1 study, the ambient temperature for the 40 days ranged from $22.97^{\circ} \mathrm{C}$ to $48.80^{\circ} \mathrm{C}$ (mean $28.81^{\circ} \mathrm{C} \pm 4.21^{\circ} \mathrm{C}$ ) at the study site as shown in figure 1 .

The air relative humidity (RH) ranged from $23.68 \%$ to $98.10 \%$ (mean $74.49 \% \pm 14.61 \%$ ) as shown in figure 2 . There were relatively high frequency of rains (15 days with humidity more than RH 90\%) during the 40-day study period due to the humid climate and wet season in Kuala Lumpur from $1^{\text {st }}$ December 2016 to $10^{\text {th }}$ January 2017.

Four stages of decomposition process were observed in Phase 1 study. There were fresh, early decomposition, advanced decomposition and skeletonisation stages. All of the decomposition processes were taken certain period of time for each control rabbits (Table 1). Time taken for grassland control exposed and wrapped carcasses to reach first sign of skeletonised stage were four days and five days respectively. Whilst freshwater controls reached initial skeletonised stage within 2 weeks for wrapped carcass. The time taken for initial sign of skeletonisation of the exposed carcass under man-made freshwater pond condition was 7 days which concurred with the findings by Heo CC et al. [33].

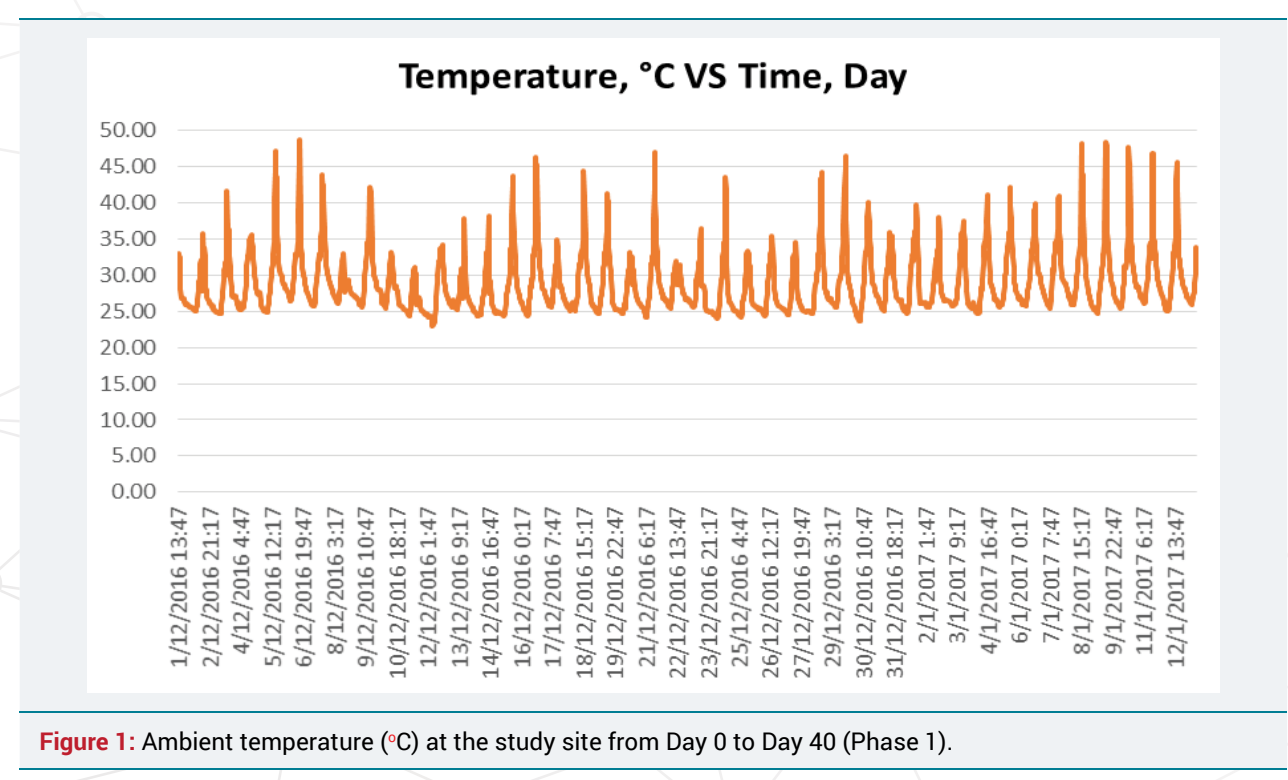


Table 2 showed the TBS scores of the samples (wrapped and cemented) compared with the controls at the Site A (Ground) and Site B (Freshwater Pond) respectively. The TBS scores of all the samples were more than half of the controls except SCm1 which was only at the ratio of 0.75:1 compared to the control on Day 6 .

Figure 3 showed the TBS scores of the controls at the Site A (Ground) and Site B (Freshwater Pond). The TBS scores kept increasing from day to day and the starting point to become plateau at different times in which equivalent to time when the skeletonisation onset at score 51. The plateau time for GC control was on Day 8, GW control and SC control plateau on Day 22. However, SW control plateau only on Day 28 onwards with the maximum score of about 49 only.

Figure 4 showed the decomposition rate of the controls at the Site A (Ground) and Site B (Freshwater Pond) in which computed using the difference of TBS score per day. The decomposition rate patterns were almost similar for all controls. It was initially increasing but peak generally once at different levels and different times in which equivalent to time of transition from early decomposition to advanced decomposition stages except the SC1 which peaked twice on Day 3 and Day 7. It was all subsequently decreased until plateau at zero roughly after 6-8 days of decomposition onset.

Table 3 showed the TBS scores between all the eight samples (wrapped and cemented) at the Site A $(\mathrm{GCm})$ and Site B $(\mathrm{SCm})$ respectively. The TBS scores were increasing from $\mathrm{GCm} 1$ (early decomposition) to $\mathrm{GCm} 4$ (skeletonisation) at Site A. It took less than 32 days to reach the initial signs of skeletonisation. However, the situation at Site B was fluctuated from SCm1 (advanced decomposition) in a risedecline-rise trending which took almost 40 days to reach the early skeletonisation stage as appeared on $\mathrm{SCm} 4$.

During the Phase 2 study, the ambient temperature for the 60 days ranged from $23.00^{\circ} \mathrm{C}$ to $53.40^{\circ} \mathrm{C}$ (mean $29.21^{\circ} \mathrm{C} \pm 4.57^{\circ} \mathrm{C}$ ) at the study site as shown in Figure 5 .

\begin{tabular}{|c|c|c|c|c|c|c|c|c|}
\hline \multicolumn{7}{|c|}{ Table 2: Comparison of TBS Score between Controls and Samples (Phase 1). } \\
\hline Day & GC1 & GCm1 & GW1 & GCm2 & SC1 & SCm1 & SW1 & SCm2 \\
\hline & Score & Score & Score & Score & Score & Score & Score & Score \\
\hline Day 4 & 44.0 & 16.5 & 30.8 & & 28.0 & & 16.8 & \\
\hline Day 6 & 50.5 & & 48.0 & 20.5 & 42.9 & 32.0 & 34.0 & \\
\hline Day 14 & 51.0 & & 48.8 & & 50.0 & & 45.0 & 19.0 \\
\hline
\end{tabular}

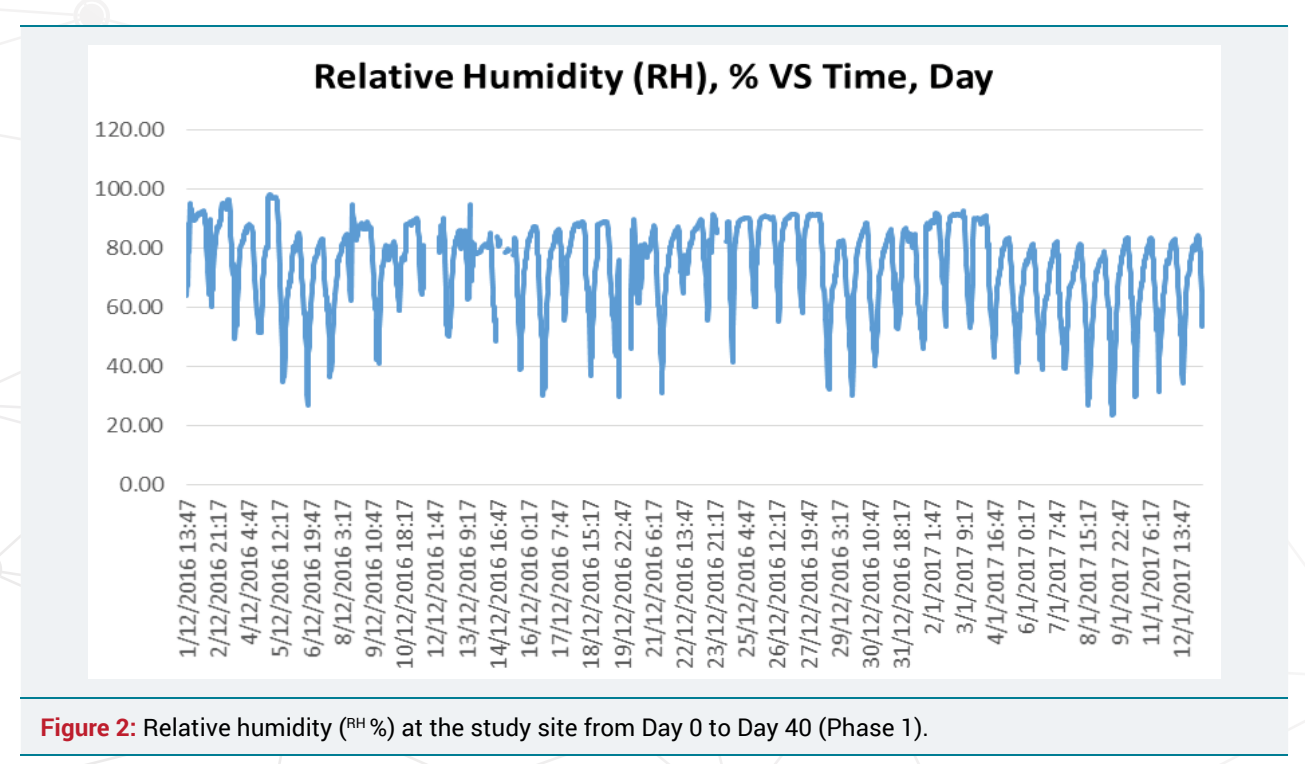



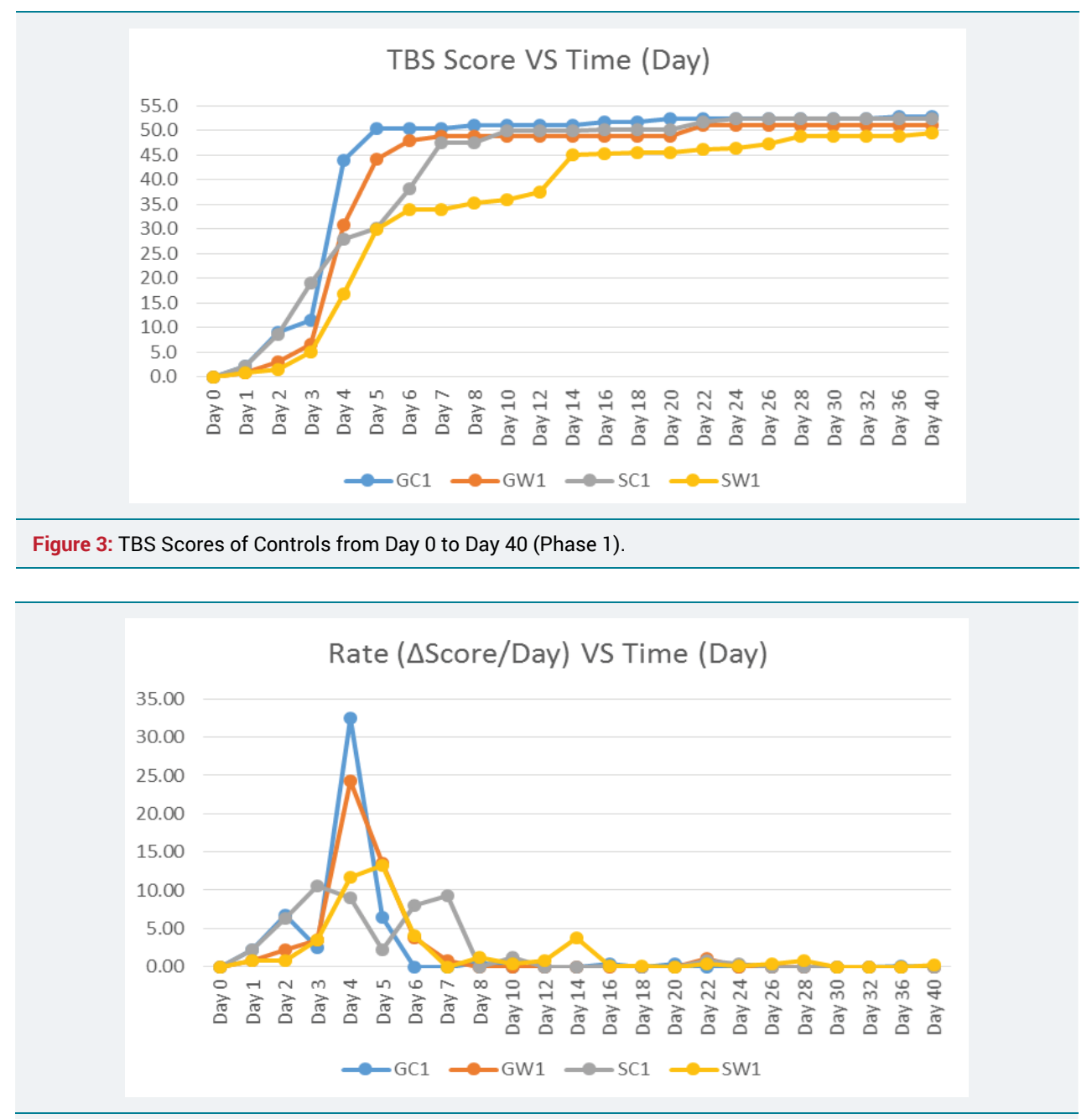

Figure 4: Decomposition Rate (TBS Score Difference per Day) of Controls from Day 0 to Day 40 for Phase 1 Study.

\begin{tabular}{|c|c|c|c|c|c|c|c|c|}
\hline \multicolumn{7}{|c|}{ Table 3: Comparison of TBS Scores between Samples (Phase 1). } \\
\hline Day & GCm1 & GCm2 & GCm3 & GCm4 & SCm1 & SCm2 & SCm3 & SCm4 \\
\hline Day 4 & Score & Score & Score & Score & Score & Score & Score & Score \\
\hline Day 6 & 16.5 & & & & & & & \\
\hline Day 14 & & & & & & & & \\
\hline Day 32 & & & 48.0 & & & & & \\
\hline Day 40 & & & & 49.5 & & & & \\
\hline
\end{tabular}

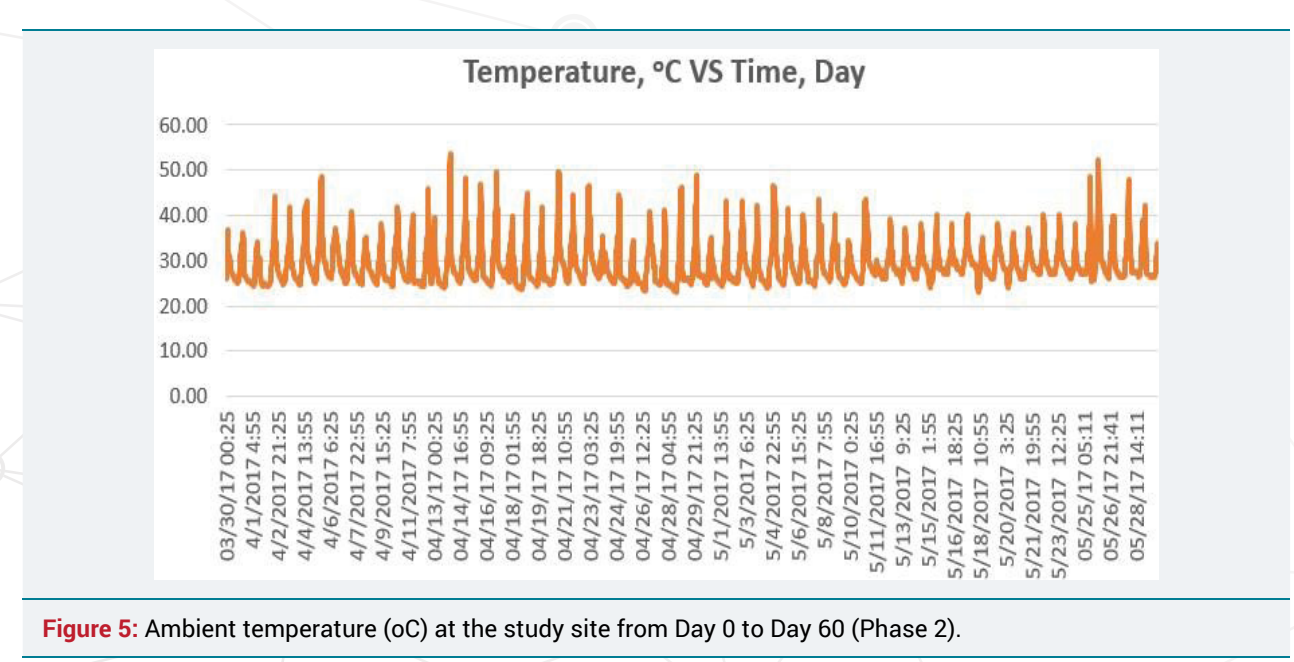


The air relative humidity (RH) ranged from $17.18 \%$ to $99.93 \%$ (mean $79.15 \% \pm 16.32 \%$ ) as shown in Figure 6. There was again high frequency of rain due to wet seasons in Kuala Lumpur.

Four stages of decomposition process were observed in the Phase 2 study. All of the decomposition processes were taken certain period of time for each control rabbits (Table 4). Time taken for control exposed carcasses to reach first sign of skeletonised stage was about 7-8 days i.e. 4 times faster than the wrapped and cemented samples.

Figure 7 showed the average TBS scores of the controls and samples. The TBS scores kept increasing from day to day and the starting point to become plateau at different times in which equivalent to time when the skeletonisation onset at score 51 . The plateau time for controls and samples were on Day 24 and Day 48 respectively.

Figure 8 showed the decomposition rate of the controls and samples in which computed using the difference of TBS score per day. The decomposition rate pattern was different for both controls and samples. For control, it was increasing and peak once on Day 4-8 equivalent to time of early decomposition stage. It was subsequently decreased until plateau at zero roughly after 24 days of decomposition onset as skeletonisation started.

Nevertheless, the decomposition rate pattern for samples were rare in appearance where it was in continual up and down values. Basically, the decomposition rate peaks at the transition of each decomposition stages including Day 4, Day 12 and Day 26. It was relatively high fluctuation at the beginning compared to the late decomposition process.

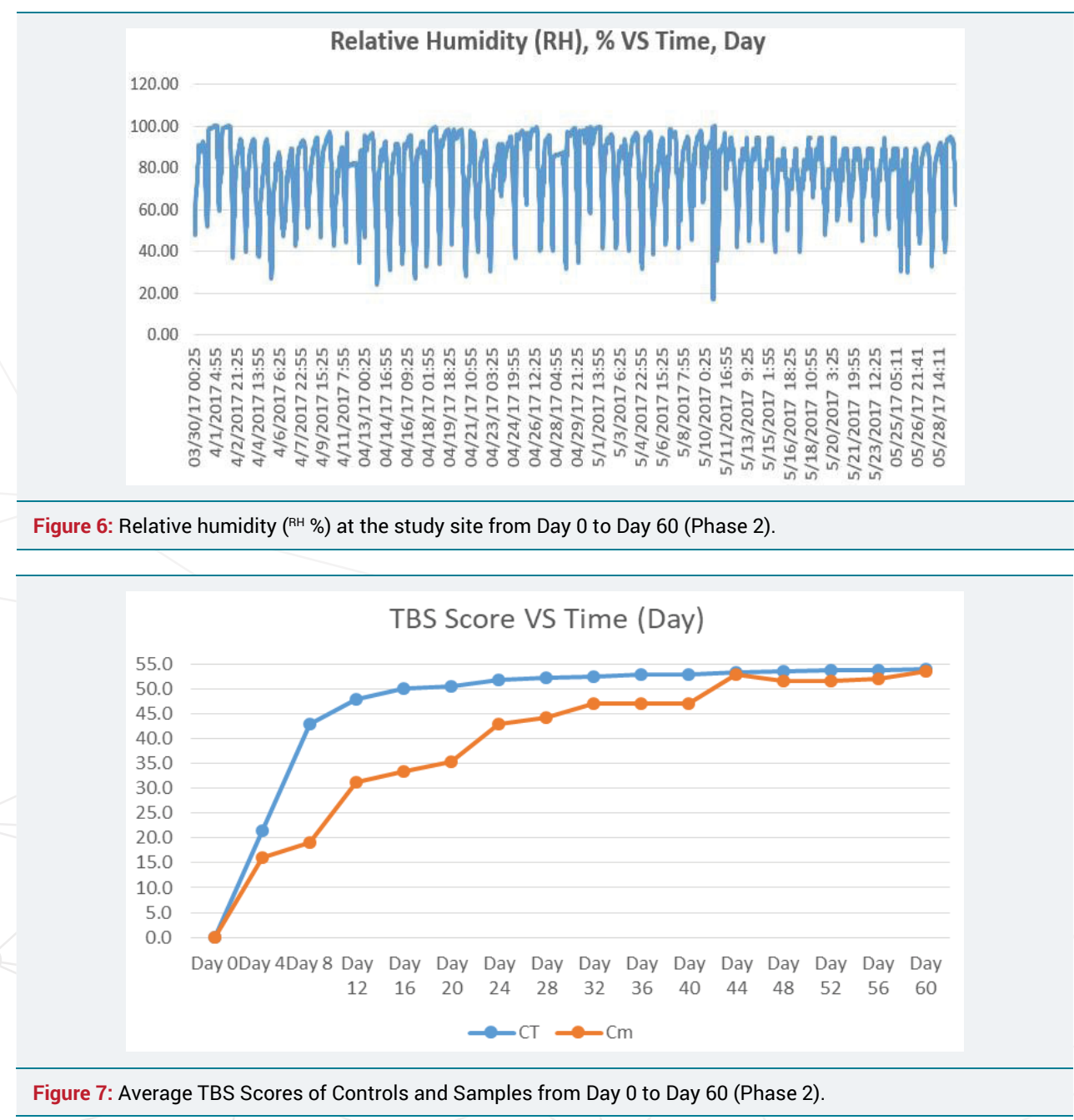




\begin{tabular}{|c|c|c|}
\hline Stage & CT & $\mathrm{Cm}$ \\
\hline & Day & Day \\
\hline Fresh & $0-1$ & $0-3$ \\
\hline Early Decomposition & $2-5$ & $4-8$ \\
\hline Advanced Decomposition & $6-7$ & $9-24$ \\
\hline Skeletonisation & $8-24$ & $25-48$ \\
\hline
\end{tabular}

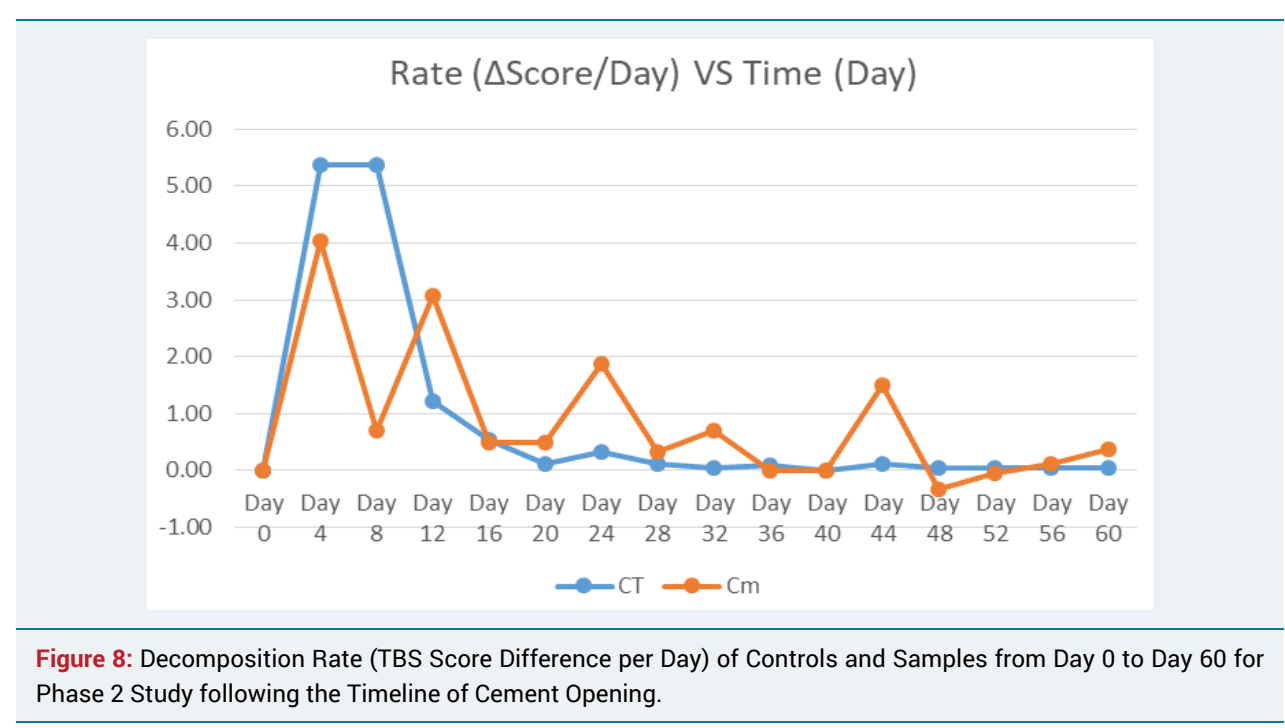

\section{DISCUSSION}

Taphonomic study in Kuala Lumpur showed the ambient temperature of site A and site B were high, stable and displayed same data distribution pattern (Figure 1). Ambient temperature was vital and influential in decomposition process [5,34]. Thus, faster rate of decomposition was observed in high ambient temperature [35]. The ambient temperature of Kuala Lumpur was always over $25^{\circ} \mathrm{C}$ during the study. Thus it has been promoting faster decomposition rate on both the carcasses.

The air relative humidity in Kuala Lumpur was high and always above 30\% during the study (Figure 2). The humidity was higher in the morning and late afternoon if compare to noon due to warming effects by the sun heat. Kuala Lumpur displayed Equatorial climate characteristic. Thus, it would have accelerated the decomposition process of Oryctolagus cunicullus. Cadaver had $60 \%$ to $80 \%$ water content inside the tissue. During the putrefaction process, there was an antagonism effect of water between the decomposition and drying process [36]. In an extremely humid condition, decomposition process would be slowed down due to the saturated water in the tissue [34]. On the other hand, humidity was positively correlated with the insect activity [5]. In some equatorial or tropical countries, the wet or rainy season have caused the more rapid decomposition compared to dry season [36]. It showed common decomposition rate for both seasons during the fresh and bloated stage, however the conversion of later decaying stages till the dry stage was relatively faster during the wet or rainy season. In this study, the adult flies were reduced greatly during the rain but the larvae were still actively scavenging on the carcasses.

In this study, four controls of Oryctolagus cunicullus displayed the four stages of decomposition process. Each stage of it displayed certain time period (Table 1). The presence of freshwater had also implied significant difference compared to the ground by 2 times (exposed control) and 3 times (wrapped control) slower rate to reach first sign of skeletonised stage. The putrefaction process will alter the surroundings and 
eventually promote the microorganism activity producing the decomposition odour that consequently attracting the dipteran to accelerate the process. Physical barrier wrapping factor and cementing factor might have played an important role to prevent the dipteran activity [25,37]. Even though time taken were not significantly different for ground exposed and wrapped control carcasses to reach first sign of skeletonised stage, it was significant under freshwater as wrapping factor delay the decomposition by 2 times. It was explained by Charabidze $D$ et al. [38], carcasses with low accessibility took longer to be accessed by the necrophagous flies.

Additionally as portrayed in table 2, we could observe the significant difference of decomposition process between the controls and the samples on Day 4 at the Site A. Cemented samples were 2 times and 2.5 times slower compared to wrapped control and exposed control respectively. The similar pattern was observed on the decomposition rate between the controls and samples at the Site B on Day 14. As such the cementing factor have superseded the wrapping factor due to its stronger physical barrier effect as show in statistics analysis by using Multiple-way ANOVA as shown in figure 9 where $p=0.031, p<0.05$. However, it was not significantly different comparing with both wrapped control and exposed control on Day 6. It could be due to some variation on the scoring system between observers and decomposition variation between the samples. Based on the ground control (GC) which took only 4 days to start skeletonised (Table 3), we could interpret that cemented samples took almost 8 times and 10 times of total number of days to reach the similar TBS scores reflecting the early skeletonisation stage at Site A and Site B respectively. However, Phase 2 study has demonstrated more accurately on the decomposition rate of the cemented samples. It showed that wrapping and cementing factors have delayed the decomposition process of the rabbit carcasses about 4 times to reach the initial stage of skeletonisation compared to the control carcasses.

Within the control and sample carcasses (Figure 3 and Figure 7), the TBS scores increased from the initial stages of decomposition and become plateau after advanced decomposition. This could be due to the onset of skeletonisation and the reduction of flesh available after advanced decomposition. As shown in figure 4, the decomposition rate (score per day) peaked around 3-5 days and decreasing to almost zero after Day 6-8 where all the larvae have entered the third instar stage where active feeding might have slowed down. However as shown in figure 8, the decomposition rate peaks at the transition decomposition stages could be due to the transition of different stages of the maggot developments.

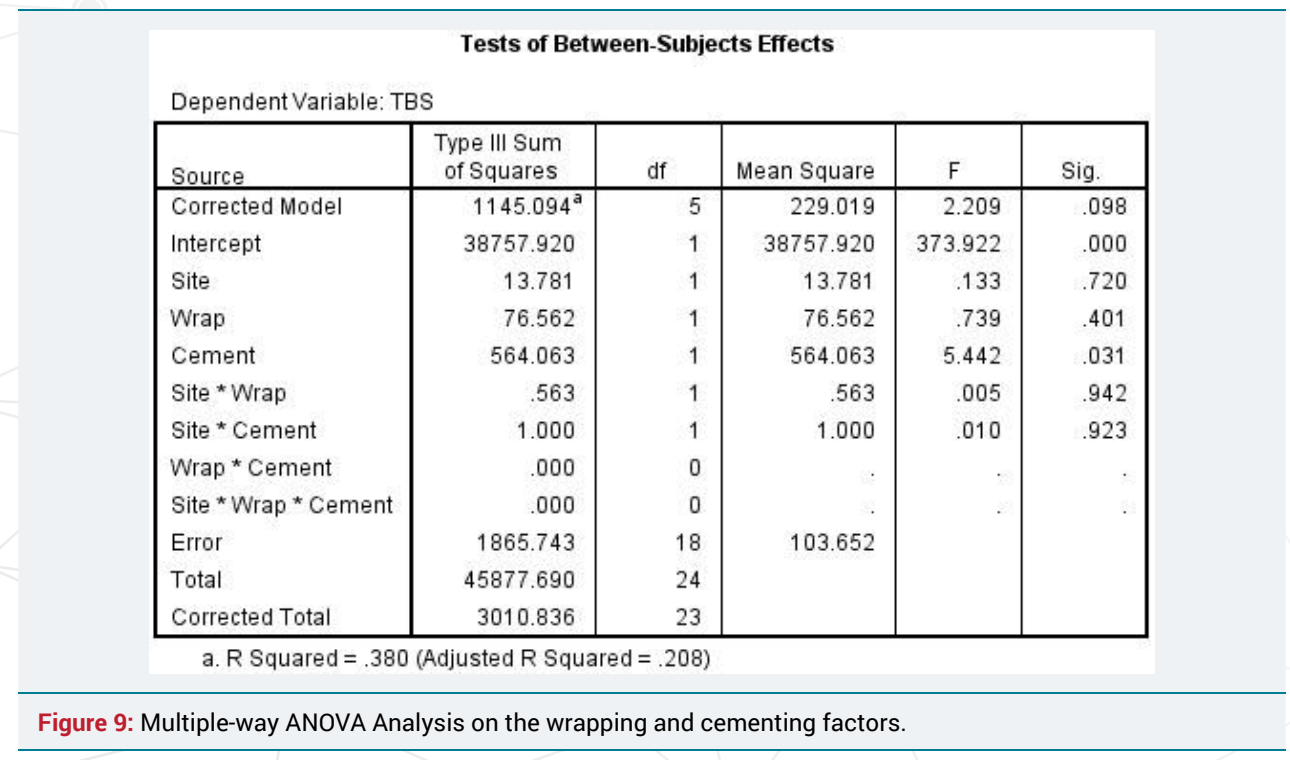


First emerged instar larvae initially fed on fluid exuded from only the control carcasses. The first instar larvae was usually found at the mouth region and orifices [39]. Majority of the species encountered were Chrysomya megacephala and Chrysomya rufifacies especially at Site A. The maggot mass was then increased significantly in accordance to the emergence of the third instar larvae [35]. Increased decomposition rate and biological activity were directly proportionate to the increased maggot mass [5]. When the remains stage commenced, there was depletion of tissue for maggot consumption and all maggots had fully developed into adult flies. Chrysomya megacephala dominated on the floating carcasses whilst the sunken or immersed carcasses were further consumed by rat-tailed flesh fly called Sarcophaga haemorrhoidalis. However, there was totally no insect activity within all the cemented samples. Nevertheless, the microorganism activity had been actively putrefying the cemented samples at slower rate compared to exposed and wrapped controls.

Despite many decades of research, accuracy in estimation of the time of death has not significantly improved, and no single method can be reliably used to accurately estimate the time of death which have contributed to the limitation of this study. It also dependent on multiple circumstantial and environmental factors. The accuracy and precision of the estimate decrease as the PMI increases. Taphonomic studies regularly employ animal analogues for human decomposition due to ethical restrictions relating to the use of human tissue. Only some researches has been conducted on human bodies, but many relevant conclusions may be drawn regarding the expected post-mortem changes in animals and the estimation of the PMI. The veterinary pathologist should have used great caution when attempting to extrapolate data and apply in humans [40].

Another limitation encountered especially the carcasses in the freshwater pond whereby they were found floating from the initial study and subsequently sunken during the advanced decomposition stage. Skin sloughing promoted the formation of adipocere. Freshly formed adipocere was able to delay the appearance of the later decomposition stages explaining why the carcasses were in relatively good condition and it would have affecting the TBS system. Early stage adipocere was correlated to ADD and that its formation on submerged remains was more likely to occur after 630 ADD. Some researchers used total aquatic decomposition score (TADS) to replace the TBS system for ADD prediction and also post-mortem submersion interval (PMSI) derivation [41].

\section{CONCLUSION}

In conclusion, the taphonomic study in Kuala Lumpur showed that four stages of decomposition is clearly defined and each of the stages taken certain time period. The equatorial or tropical climate in Kuala Lumpur has increased the rate of decomposition process. Time taken for ground control exposed and wrapped carcasses to reach first sign of skeletonised stage were four days and five days respectively. Whilst freshwater controls reached initial skeletonised stage within one week for exposed carcass and two weeks for wrapped carcass. Within the control carcasses, TBS scores increased from initial stages of decomposition and become plateau after advanced decomposition. The decomposition rate (score per day) peaked around 3-5 days and decreasing to almost zero after Day 6-8. The cementing factor have superseded the wrapping factor due to its stronger physical barrier effect to slow down the decomposition more than half compared to controls based on Multiple-way ANOVA test. Cemented samples took almost eight times longer at Site A and ten times longer at Site B comparing with their respective controls in term of time taken to reach the similar TBS scores reflecting the early skeletonisation stage. Phase 2 study has demonstrated more accurately on the decomposition rate of the cemented samples. It showed that wrapping and cementing factors have delayed the decomposition process of the rabbit carcasses about 4 times 
to reach the initial stage of skeletonisation compared to the control carcasses. There was absence of insect activity within the cemented samples, hence the microorganism activity would be the only contributor to the decaying process within the cemented samples at slower rate compared to exposed and wrapped controls.

\section{ACKNOWLEDGEMENT}

A great appreciation to the contribution from National Institute of Health (NIH) for research registration (NMRR-16-500-29821), reviewing the proposal and approving the NIH grant for the financial support throughout the study. Sincere gratitude towards Animal Care and Use Committee (ACUC) for the animal ethics approval ACUC/KKM/02(7/2016). Last but not least the Director of Hospital Kuala Lumpur and Director of National Institute of Forensic Medicine, Malaysia for allowing the use of study site throughout the study.

\section{REFERENCES}

1. Ururahy-Rodrigues A, Rafael JA, Wanderley RF, Marques H, Pujol Luz JR. Coprophanaeus lancifer (Linnaeus, 1767) (Coleoptera, Scarabaeidae) activity moves a man-size pig carcass: Relevant data for forensic taphonomy. Forensic Science International. 2008; 182: 19-22. Ref.: https://goo.gl/VmxxEy

2. Haglund WD, Sorg MH. Advances in Forensic Taphonomy: Method, Theory, and Archaeological Perspectives CRC Press. Ref.: https://goo.gl/NZ942B

3. Kormondy EJ, Brown DE. Fundamentals of Human Ecology. Pearson. 1998. Ref.: https://goo.gl/D7Uf2B

4. Gifford DP. Taphonomy and paleoecology: A critical review of archaeology's sister disciplines. Advances in Archeological Method and Theory ed. M.B. Schiffer. 1981. Ref.: https://goo.gl/PGHhYX

5. Mann RW, Bass WM, Meadows L. Time since death and decomposition of the human body: variables and observations in case and experimental field studies. J Forensic Sci. 1990; 35: 103-111. Ref.: https://goo.gl/Enm8EZ

6. Benninger LA, Carter DO, Forbes SL. The biochemical alteration of soil beneath a decomposing carcass. Forensic Sci Int. 2008; 180: 70-75. Ref.: https://goo.gl/Uejcxz

7. Coe M. The decomposition of elephant carcasses in the Tsavo (East) National Park, Kenya. Journal of the Arid Environments. 1978; 1: 71-86. Ref.: https://goo.gl/sp2Eqx

8. Lyman RL. Vertebrate Taphonomy. 1994. Ref.: https://goo.gl/1rxTbN

9. Carly MS. An analysis of decomposition rates on outdoor surface variations in central Texas. Graduate Council of Texas State University-San Marcos. 2009. Ref.: https://goo.gl/ST6yJn

10. Ferreira MT, Cunha E. Can we infer post mortem interval on the basis of decomposition rate? A case from a Portuguese cemetery. Forensic Sci Int. 2013; 226: e1-e6. Ref.: https://goo.gl/pUaNQz

11. Azwandi A, Abu Hassan A. A preliminary study on the decomposition and dipteran associated with exposed carcasses in an oil palm plantation in Bandar Baharu, Kedah, Malaysia', Tropical Biomedicine, 2009; 26: 1-10. Ref.: https://goo.gl/rPyBix

12. Heo CC, Mohamad AM, Ahmad Firdaus MS, Jeffery J, Baharudin O. A preliminary study of insect succession on a pig carcass in a palm oil plantation in Malaysia. Trop Biomed. 2007; 24: 23-27. Ref.: https://goo.gl/5qmyWz

13. Stokes KL. Forbes SL, Tibbett M. Human Versus Animal: Contrasting Decomposition Dynamics of Mammalian Analogues in Experimental Taphonomy. J Forensic Sci. 2013; 58: 583-591. Ref.: https://goo.gl/3d43sN

14. Zhou C, Byard RW. Factors and processes causing accelerated decomposition in human cadaversAn overview. J Forensic Leg Med. 2011; 18: 6-9. Ref.: https://goo.gl/gbkUtG

15. Szymon M, Daria B, Szymon K, Krzysztof S. Insect succession and carrion decomposition in selected forests of Central Europe. Forensic Sci Int. 2010; 194: 85-93. Ref.: https://goo.gl/PX49b9

16. Simmons T, Adlam RE, Moffatt C. Debugging Decomposition Data-Comparative Taphonomic Studies and the Influence of Insects and Carcass Size on Decomposition Rate. Journal of Forensic Sci. 2010; 55: 8-13. Ref.: https://goo.gl/W5yUiJ 
17. Sutherland A, Myburgh J, Steyn M. The effect of body size on the rate of decomposition in a temperate region of South Africa. Forensic Sci Int. 2013; 231: 257-262. Ref.: https://goo.gl/Qsw31z

18. Kelly JA, Linde T, Anderson GS. The Influence of Clothing and Wrapping on Carcass Decomposition and Arthropod Succession during the Warmer Seasons in Central South Africa. Journal of Forensic Sci. 2009; 54: 1105-1112. Ref.: https://goo.gl/PJL2gj

19. De Donno A, Campobasso CP, Santoro V, Leonardi S, Tafuri S, et al. Bodies in sequestered and non-sequestered aquatic environments: A comparative taphonomic study using decompositional scoring system. Sci \& Justice. 2014; 54: 439-446. Ref.: https://goo.gl/xP37CW

20. Humphreys MK, Panacek E, Green W, Albers E. Comparison of Protocols for Measuring and Calculating Post-mortem Submersion Intervals for Human Analogs in Fresh Water. Journal of Forensic Sci. 2013; 58: 513-517. Ref.: https://goo.gl/34CaKv

21. Sasha CV, David FC, lan RD. Decomposition and insect succession of clothed and unclothed carcasses in Western Australia. Forensic Sci Int. 2011; 211: 67-75. Ref.: https://goo.gl/ZGc7eM

22. Eline MJS, John D, Jessica D, Tatiana I, Sarah L, et al. Effects of hydrated lime and quicklime on the decay of buried human remains using pig cadavers as human body analogues. Forensic Sci Int 2012; 217: 50-59. Ref.: https://goo.gl/ZzVerZ

23. Heather AT. Effects of lime of the decomposition rate of buried remains. Human Biology at the University of Indianapolis. 2000; 1-2. Ref.: https://goo.gl/yLuxFc

24. Cement \& Concrete Product Manufacturing industry profile. First Research. 2016. Ref.: https://goo.gl/K3GvSZ

25. Global Concrete and Cement Market-Key Trends and Opportunities to 2017. Ref.: https://goo.gl/YUxHqs

26. Samuel OF, Moray DN. Suitability of cement combinations for carbonation resistance of structural concrete. Ref.: https://goo.gl/F5CKqS

27. Campobasso CP, Di Vella G, Introna F. Factors affecting decomposition and Diptera colonization. Forensic Sci Int. 2001; 120: 18-27. Ref.: https://goo.gl/x4XBp5

28. Gibelli D, Di Giancamillo A, Taborelli A, Porta D, Andreola S, et al. Burial of piglet carcasses in cement a study of macroscopic and microscopic alterations on an animal model. Am J Forensic Med Pathol. 2013; 34: 43-49. Ref.: https://goo.gl/jHgfPt

29. Weidner LM, Monzon MA, Hamilton GC. Death eaters respond to the dark mark of decomposition day and night: observations of initial insect activity on piglet carcasses. Int J Legal Med. 2016; 130 1633-1637. Ref.: https://goo.gl/GkppXq

30. Zurawski KN1, Benbow ME, Miller JR, Merritt RW. Examination of nocturnal blow fly (Diptera: Calliphoridae) oviposition on pig carcasses in mid-Michigan. J Med Entomol. 2009; 46: 671-679. Ref.: https://goo.gl/85P7Gk

31. Haskell N, McShaffrey D, Hawley D, Williams R, Pless J, et al. Use of aquatic insects in determining submersion interval. J Forensic Sci, 1989; 34: 622-632. Ref.: https://goo.gl/iRDtQU

32. Nawrocka M, Frątczak K, Matuszewski S. Inter-Rater Reliability of Total Body Score -A Scale for Quantification of Corpse Decomposition. J Forensic Sci. 2016; 61: 798-802. Ref.: https://goo.gl/Pzx9VG

33. Heo CC, Mohamad AM, John J, Baharudin O. Insect succession on a decomposing piglet carcass placed in a man-made freshwater pond in Malaysia. Trop Biomed. 2008; 25: 23-29. Ref.: https://goo.gl/Xkzk5Y

34. Joy JE, Liette NL, Harrah HL. Carrion fly (Diptera: Calliphoridae) larval colonization of sunlit and shaded pig carcasses in West Virginia, USA. Forensic Sci Int. 2006; 164: 183-192. Ref.: https://goo.gl/HkDYdB

35. Aufderheide AC. Soft tissue palaeopathology-an emerging subspecialty. Hum Pathol. 1981; 12: 865867. Ref.: https://goo.gl/7EkFNL

36. Azwandi A, Abu Hassan A. A preliminary study on the decomposition and dipteran associated with exposed carcasses in an oil palm plantation in Bandar Baharu, Kedah, Malaysia. Trop Biomed. 2009; 26: 1-10. Ref.: https://goo.gl/H4JmeZ

37. Kelly JA, van der Linde TC, Anderson GS. The influence of clothing and wrapping on carcass decomposition and arthropod succession during the warmer seasons in central South Africa. $J$ Forensic Sci. 2009; 54: 1105-1112. Ref.: https://goo.gl/JXwoDM 
38. Charabidze D, Hedouin V, Gosset D. An experimental investigation into the colonization of concealed cadavers by necrophagous blowflies. J Insect Sci. 2015; 24: 149. Ref.: https://goo.gl/B3L5A3

39. Klotzbach $\mathrm{H}$, Schroeder $\mathrm{H}$, Augustin $\mathrm{C}$, Pueschel $\mathrm{K}$. Information is everything-A case report demonstrating the necessity of Entomological knowledge at the crime scene. J Forensic Med Toxicol. 2004; 5: 19-21. Ref.: https://goo.gl/7kuaKS

40. Brooks JW. Post-mortem Changes in Animal Carcasses and Estimation of the Postmortem Interval Vet Pathol. 2016; 53: 929-940. Ref.: https://goo.gl/iFBK9b

41. De Donno A, Campobasso CP, Santoro V, Leonardi S, Tafuri S, et al. Bodies in sequestered and nonsequestered aquatic environments: a comparative taphonomic study using decompositional scoring system. Sci Justice. 2014; 54: 439-446. Ref.: https://goo.gl/maiJ7j 